\title{
The Nature and Extent of Domestic Construction Program Outsourcing
}

\author{
Barton Grasso, S.M.ASCE ${ }^{1}$, William Rasdorf, Ph.D., P.E., F.ASCE ${ }^{2}$, Mark Bridgers ${ }^{3}$
}

\begin{abstract}
The sourcing of a construction program has always been a fluid process for many construction owners. A construction owner must balance the performance of all construction functions between internal staff and external service providers. Described herein are recent sourcing trends of construction programs identified through a survey of nonresidential construction owners. The survey data is representative of 170 respondents with varying demographic characteristics that account for about $\$ 72$ billion in annual construction spending. Included are outsourcing trends of specific functions across the construction life-cycle and the sourcing strategy employed for each. A comparison of the outsourcing volume reported and the sourcing strategy employed is presented. A clear relationship between the amount of outsourcing and the sourcing strategy employed for the performance of construction is shown. The paper provides the academic community with new outsourcing data for construction lifecycle functions. It also provides contractors with new information about the current behavior of construction owners while providing owners with a better understanding of the relationship between sourcing and outsourcing.
\end{abstract}

CE Database subject headings: Owners; Organizations; Life Cycle; Capital Improvement, Program Management, Outsourcing.

${ }^{1}$ M.S. Graduate, Department of Civil, Construction, and Environmental Engineering, North Carolina State University, Campus Box 7908, Raleigh, NC 27695. Email: bart.grasso@gmail.com

${ }^{2}$ Professor, Department of Civil, Construction, and Environmental Engineering, North Carolina State University, Campus Box 7908, Raleigh, NC 27695. Email: rasdorf@ ncsu.edu

${ }^{3}$ Senior Consultant, FMI Corporation, 5171 Glenwood Avenue, Suite 200, Raleigh, NC 27612. Email: mbridgers@fminet.com 


\title{
The Nature and Extent of Domestic Construction Program Outsourcing
}

\author{
Barton Grasso, S.M.ASCE ${ }^{1}$, William Rasdorf, Ph.D., P.E., F.ASCE ${ }^{2}$, Mark Bridgers ${ }^{3}$
}

\section{INTRODUCTION}

Any business has the option of performing some or all of the functions of their business process either with in-house staff or by utilizing an external service provider. The process of hiring an external service provider is referred to as outsourcing. Outsourcing is defined as, "the act of transferring some of a company's recurring internal activities and decision rights to outside providers, as set forth in a contract" [Greaver 1999].

As large corporations and government institutions (who are also owners of construction) look to streamline their business processes, outsourcing has become a popular option. Owners of large capital facilities often seek specialized contractors to help them complete some or all phases of the construction life-cycle. Owners who outsource any portion of their construction activity must decide on the sourcing strategy to be employed. The number of service providers that the owner selects from for each phase of the construction life-cycle is a strong indication of the sourcing strategy. Owners of construction should have a sourcing strategy that matches their outsourcing needs.

A survey was conducted to determine the amount of outsourcing that occurs across multiple project functions and the number of service providers used in sourcing each function. The results of the survey and the subsequent analysis and conclusions are presented in this paper. This paper presents the results of a study to:

- Benchmark the current outsourcing trends within construction.

- Benchmark the current number of service providers used when sourcing each phase of construction.

- Establish the relationship between the amount of outsourcing and the sourcing strategy employed.

The outcome of this paper should be to aid in understanding how construction owners are sourcing their construction programs. The work itself should provide a benchmark that can be looked at again in a few years. For the academic community there is hard data available from the survey. Of particular interest to researchers is a discovery that the performance of design and the performance of construction were both heavily outsourced. The paper quantifies the extent of that outsourcing. For the contractor, this paper provides insights into owner behavior, especially how owners approach the procurement of services for each of the life-cycle functions. For owners, insight is gained into the relationship between sourcing and outsourcing that is prevalent in the construction industry today. They can also determine some of the strategies that other owners are using with respect to sourcing.

\section{LITERATURE REVIEW}

Research on the sourcing of a construction program has been scarce and the most notable studies were performed in the 1990s and relate to outsourcing. According Bryant [Bryant 2006], "current research being performed by academia on outsourcing has largely ignored the 
architecture/engineering/construction $(\mathrm{A} / \mathrm{E} / \mathrm{C})$ industry, tending to focus more on high-tech, manufacturing, and financial services." Bryant goes on to state the reason for the limited research on outsourcing within the $\mathrm{A} / \mathrm{E} / \mathrm{C}$ industry is because many of the firms within the industry are small or medium size firms. Without the large publicly traded firms and with the exceptional fragmentation of the industry any interest in outsourcing studies by the academic community is unlikely [Bryant 2006].

The Center for Construction Industry Studies (CCIS) published a report on owner outsourcing trends in 2001 that reviewed outsourcing trends during the period of 1994 to 1998 and focused on three project functions: pre-project planning, design, and procurement [Gibson et al. 2001]. Table 1 provides the results of the outsourcing data for the CCIS study. The outsourcing totals for each individual project function and the average value, from 1994 to 1998, are given. It is apparent from Table 1 that the Construction Industry Institute (CII) study found that design and procurement were the most heavily outsourced at $80 \%$. It should be noted that the CCIS study was focused on heavy industrial projects obtained from the CII Benchmarking database. Our study is based on a larger number of market sectors. These will be discussed further below.

The outsourcing data is presented as a percentage of all activity related to the function, and the year in which the high and low values were determined is given in parenthesis next to the value. For example, during the five years of the study, the function pre-project planning experienced the highest amount of outsourcing in 1997 when $34 \%$ of the work was outsourced. The lowest percentage of outsourcing for pre-project planning work occurred in 1998 at $6 \%$. The average amount of outsourcing for pre-project planning was $20 \%$.

Another study of outsourcing trends was also undertaken in the mid 1990s by Bon and Luck that focused on corporate real estate management (CREM) [Bon and Luck 1999]. In their study Bon and Luck determined the percentage of design, construction, facilities, and maintenance management that were performed in-house from 1993 to 1998. The study determined that facilities management was performed in-house more often than any of the other functions $(68 \%)$, while design management was performed in-house the least $(50 \%)$.

The mean percentage of responses for the incidence of CREM functions over the six year period of the Bon and Luck study is given below in Table 2. Table 2 also incorporates a column that includes the average percentage of time that each function was performed in-house and a column that includes the corresponding average percentage of time the function was outsourced. For example, the percentage of design management that was performed in-house in 1993 was $33 \%$. Also, the average percentage of time design management was performed in house from 1993 to 1998 was $50 \%$ while the average amount outsourced during the same time period was also $50 \%$.

While it would be beneficial to compare the CCIS study and the Bon and Luck study that is not possible because of the difference in functions. In our work we address essentially all of the functions in these two studies combined, except for procurement. This paper is thus able to make a comparison between the results presented herein and the results of both the CCIS study and the Bon and Luck studies.

\section{RESEARCH METHODOLOGY AND SURVEY DEVELOPMENT}


Due to the age of the relatively limited number of related studies and the minimal focus on sourcing strategies, a recent study was conducted to attempt to identify current outsourcing trends within the construction industry over the past decade, to establish new outsourcing data for project functions that have not previously been studied, and to determine the sourcing strategies related to the outsourcing of each function. In conjunction with FMI Corporation (a construction consulting firm) and the Construction Management Association of America (CMAA), a survey was developed that focused on the current outsourcing and sourcing strategies of non-residential construction owners.

The 2006 FMI/CMAA Annual Survey of Owners was the seventh in a series of surveys performed by FMI and CMAA. Past surveys of owners have historically focused on construction management. The 2006 survey focused on program management and the management of a construction program. The survey instrument was developed through a series of meetings with a focus group of industry professionals. The focus group consisted of members who were both extremely knowledgeable and experienced within the realm of program management in construction.

The targeted participants for the survey were owners of construction. In order to reach the largest number of possible survey respondents several professional organizations within the construction industry were contacted. Each of the organizations contacted represents a large number of construction owners from a broad range of market sectors. Through professional contacts established by FMI and CMAA, the following organizations were contacted to request assistance in accessing their membership base:

- Construction Management Association of America (CMAA)

- Construction Owners Association of America (COAA)

- Construction Users Roundtable (CURT)

- Health Facility Institute (HFI)

- Council of Education Facility Planners International (CEFPI)

All of the organizations agreed to take part in the survey. In addition to the membership base of these professional organizations, contacts within the FMI internal database were also contacted to take part in the survey. A review of all FMI construction owner contacts was performed. Contacts were selected by market sector and their potential to respond to the survey.

The survey was disseminated either by a paper copy through postal mail or as an internet link to an online version of the survey emailed to select participants. Paper copies of the survey instrument were sent to individuals within the FMI database for which an email address was not available. All other potential survey respondents received an email invitation to participate in the survey.

An email was provided to each of the professional organizations that included an introductory statement explaining to the participants the purpose of the survey and the importance of their involvement. The introductory statement was followed by a link to the survey's URL address. The responsibility of forwarding the survey to the membership base of each organization rested with the administrative staff of each respective organization. Because each organization's membership list is proprietary the total number of recipients was not known. 
The results of the survey were collected via the same medium they were distributed. A total of 170 responses to the 2006 FMI/CMAA Annual Survey of Owners were received. However, it is important to observe that not every respondent answered every question, thus the reader may see varying numbers of survey responses for each question, most typically 170, 169, 168, or 167.

The confidence interval for the survey responses was not calculated. According to Galloway [2006], a confidence interval should not be calculated for a voluntary survey because, "a confidence level calculation is not valid for a voluntary survey because underlying factors could exist as to why some companies chose to respond and others did not." However, demographic data for each survey respondent was collected in order to assure that the survey data was an appropriate representation of this segment of the construction industry.

Demographic data was collected on the type, market sector, projects started per year, and annual construction spending of the construction programs surveyed. Figure 1 shows the percentage breakdown of the survey respondents by organization type. Of those identified the largest were:

- Publicly traded stock corporation $(27 \%)$

- Municipal authority (16\%)

- State agency $(14 \%)$

A high percentage of respondents (25\%) classified their organization as 'other.' A large majority of the respondents who classified their organization as 'other' provided a clarification of their response. A majority of the respondents designated their organization as a K-12 public school district, a university, a not-for-profit private company, or various other responses. There was no determination in the survey of the role of specialized construction. Rather, the survey focused instead only on the different types of market sectors.

Table 3 presents the number of responses and the percentage breakdown of the market sector in which each construction program primarily operated. The education sectors led by far followed by the energy and private office and professional sectors. For example, 35.5\% (60/169) of respondents indicated that they work in the education sector. It should also be noted that these same respondents also work in other sectors. Thus, the table tells us about the survey respondents; it does not report on the construction industry as a whole. The next three sectors were all related to public projects: water supply and waste water facilities, public safety and administration facilities, and highways and streets. Thus, the projects mirrored what one would normally expect from the federal, state, and municipal owners identified in Figure 1.

Figure 2 presents the percentage breakdown of the respondents by the total number of projects started per year by each. The figure shows that just over $35 \%$ start fewer than 20 projects each year, $40 \%$ start 20 to 100 projects, and approximately $25 \%$ start over 100 projects each year.

The construction spend data that was obtained from the survey respondents was used to gain an idea of the percentage of the construction industry represented by the survey respondents. The total amount of construction spend for all survey respondents was found by the summation of each response multiplied by the total number of respondents. The summation of all low end and high end values was used to determine a range of spending for all survey respondents. Only the 
low end value for the response of $>\$ 1 \mathrm{~B}$ was used since it is not possible to determine a high end value because specific numbers related to spending were not provided.

The respondents to the 2006 FMI/CMAA Annual Survey of Owners were found to have a cumulative total annual construction spend between about $\$ 37$ billion and $\$ 72$ billion. Considering that the construction market totaled \$1.14 trillion in 2005 [Simonson 2006] and that the non-residential market accounted for about 52 percent of industry revenues, the nonresidential construction market put in place an estimated $\$ 590$ billion in 2005 [Datamonitor 2006]. Thus, the survey population accounts for a sufficient percentage of the overall nonresidential construction dollars spent in the United States. Table 4 presents the results and calculations for the data obtained on annual construction spend.

\section{RESULTS}

The 2006 FMI/CMAA Annual Survey of Owners contained multiple questions related to the outsourcing of construction programs, sourcing strategies of construction owners, defining the role of a program manager, and the hiring of a program manager. This paper reviews the results of the questions related to the first two of these four focus areas, the outsourcing of a construction program and the sourcing strategy used by construction owners to do so. The results of the survey responses were similar to past research and to industry perception. The following sections detail the outcome of the survey.

\section{Owner Outsourcing}

The questions related to the outsourcing of construction were first directed at determining the amount of outsourcing that occurs across multiple functions of the construction life-cycle. A series of functions that covered the entire construction life-cycle were identified for use within the survey. A definition for each function was also determined and accompanied the questions related to the amount of outsourcing within the survey. The functions are included in Table 5 along with their respective descriptions. The descriptions were developed by the authors and were edited by the survey focus group in order to provide clarity to each survey respondent on the meaning of each function.

Survey respondents were given a series of ranges that represented the percentage of the activity involved with each outsourced function. Ranges were used to make it easier for respondents to estimate the amount outsourcing that occurred within their organization. The response totals for each of the functions from Table 5 is presented in Table 6, segregated by range. As an example, $24 \%-1 \%$ means that this is the percentage of the work that was outsourced for each function. The entries in each cell indicate how many out of the total of 168 respondents outsourced this much.

Of particular interest in Table 6 are the number of respondents who reported outsourcing one of the functions completely $(100 \%)$ or performing the entirety of the function in house $(0 \%)$. A large percentage, $45.2 \%$ (76/168), of respondents reported outsourcing all of their construction activity (performance of construction). Thus, $45.2 \%$ of respondents do absolutely no in-house construction (and $72.6 \%((76+46) / 168)$ outsource at least $75 \%$ of their construction). Only $8.9 \%$ $(15 / 168)$ perform all of their own construction. The performance of design also had similar 
response totals, showing that $30.4 \%(51 / 168)$ of respondents outsourced all of their design work. Three functions of the construction life-cycle were performed entirely in-house by more than one in three $(>33.3 \%)$ respondents. The three functions and the respective percentage of time they were performed completely in-house are as follows:

- Oversight of Design - 36.9\% (62/168)

- Activation - 34.1\% (57/167)

- Operations and Maintenance $-34.5 \%(58 / 168)$

Note that the response totals for each function vary (168/167). As mentioned earlier, not all respondents answered every question and thus response totals vary for each question.

The average amount of outsourcing that occurred within each function of the construction lifecycle was determined from the response totals given of Table 6 . The midpoints of each range given as an answer choice were used to determine the average outsourcing. Table 7 presents the midpoints used for each range. The average amount of outsourcing for each function studied is presented in Figure 3. Figure 3 shows the percentage outsourced on the y axis as compared to the outsourced functions on the $\mathrm{x}$-axis. The average value for the percentage outsourced is shown above the respective bar for each function.

As is evident from the average amount of outsourcing totals of Figure 3, the performance of design and the performance of construction are the most heavily outsourced program management functions. The performance of design is the highest outsourced function at $77.1 \%$. All other activities were outsourced less frequently with the average outsourcing for each function typically being between $30 \%$ and $40 \%$. Operations and maintenance was the least outsourced of all construction functions at $23.7 \%$.

\section{Sourcing Strategy}

In order to better understand the sourcing strategy employed by construction owners, the number of service providers considered in the sourcing process was reviewed in the survey. The questions related to the sourcing strategy of construction owners again were organized by construction functions. Each of the functions used in the study of outsourcing was also used in the study of sourcing strategy (see Table 5). The questions related to sourcing strategy were presented in a similar format to those related to outsourcing.

Respondents were asked to report the number of service providers they selected from when sourcing each function within the construction life-cycle. The answer choices were broad and were intended to capture trends in an owner's sourcing strategy and were not meant to determine the exact number of service providers. An answer choice of N/A (not applicable) was provided for respondents that did not outsource a particular function and thus did not select external service providers. The answer choices provided to the respondents are given in Table 8 . The response totals for each of the functions is given in Table 9. Note that Table 8 answer choices can be related to the size of the pool of service providers from which an owner selects a provider. This is shown in the number of providers column. Note that these numbers can vary by organization but are representative of the concept being conveyed in the table. 
A review of the response totals highlights the fact that the sourcing strategy most often selected by the respondents was to consistently select from a small group of service providers for each project (ranging from 55-82 respondents). The only construction function for which the highest number of respondents did not select this choice was the performance of construction. For the performance of construction, the sourcing strategy selected by the largest number of respondents was to always select a different service provider for each project (71 respondents). The performance of construction has historically been sourced through a low-bid contract and this contract structure still dominates many markets today. It is thus no surprise that many owners still report selecting from a large number of service providers when sourcing the performance of construction.

A roll-up value for the overall sourcing strategy employed across all construction functions studied was also determined. The roll-up values were calculated by summing the response totals of each function and using the aggregate values to calculate the percentage of respondents to each answer choice. The percentage of responses for the sourcing roll-up is presented in Figure 4.

The roll-up response totals highlight the fact that the most predominantly used sourcing strategy is selecting from a small group of service providers which confirms the results of the response totals for each individual function. What is interesting to note is that owners do not appear to be developing strong relationships with a single service provider. Only $3.6 \%$ of the time did respondents report always using the same service provider and only $10.7 \%$ of the time respondents reported frequently using the same service provider.

\section{Relationship Between Function and Strategy}

The survey results were analyzed to determine if there was an observable relationship between the amount of outsourcing within each function and the sourcing strategy used. This was done for each function within the study. The midpoint value found in Table 7 was assigned to each outsourcing response. The corresponding average outsourcing value of all responses to the sourcing questions was determined and is reported in Table 10. For example, for the pre-design function, all the respondents who reported always selecting from a different service provider ("Different" column) also reported outsourcing on average $39.0 \%$ of the activity associated with the pre-design function. Thus, the organizations that always use a different service provider outsource $39.0 \%$ of their pre-design work. As another example, the organizations that always use the same provider for their pre-design work ("Always" column) outsource $64.2 \%$ of their work. Response number 5, or N/A, was removed from the analysis because the selection of response 5 was dependent upon the answer to the outsourcing questions.

Several relationships with sourcing strategy and outsourcing are evident from Table 10. For several of the functions it appears that as the number of service providers selected from decreases (moving from left to right across the table), the amount of outsourcing increases. This illustrates an inverse relationship between sourcing strategy and outsourcing. An inverse relationship was evident for all functions related to the management of the construction process including:

- Pre-design

- Oversight of design 


\section{- Oversight of construction}

It is evident from the data that as the amount of outsourcing increases the pool of service providers that are selected from to perform the work decreases proportionally. It is possible that as owners gain experience and establish relationships with contractors (and establish successful collaborations with providers who meet their needs), they continue to work with those providers. Thus, over time, the overall number of providers an owner works with decreases.

For several of the other functions it appears that as the number of service providers selected from decreases, the amount of outsourcing also decreases. This illustrates a direct relationship between sourcing strategy and outsourcing. A direct relationship is evident for all functions related to the performance aspects of the construction process and includes:

- Performance of design

- Performance of construction

- Operations and maintenance

Also of note from the analysis is the strength of the relationship between outsourcing and sourcing strategy that exists for each of the construction functions. Clear relationships existed for the following functions:

- Performance of design

- Oversight of construction

- Performance of construction

- Operations and maintenance

The performance of construction appeared to express the strongest relationship between sourcing strategy and outsourcing. That is, there is a clear and consistent decrease in the amount of outsourcing as the number of service providers decreases, as shown by the shaded row in Table 10. Several other functions showed a moderate relationship including pre-design and the oversight of design. No relationship between sourcing strategy and outsourcing was evident for the activation function.

\section{COMPARISON WITH PREVIOUS WORK}

The outsourcing data obtained from this study was compared to the studies performed in the mid 1990s presented earlier in this paper. Our findings correlated well with those of the CCIS study but not well with those of the CREM study.

The CCIS study [Gibson et al. 2001] on outsourcing reported the average outsourcing of preproject planning and design over the period of 1994 to 1998 to be 20 percent and 80 percent respectively. Considering the outsourcing data obtained in this survey in 2006 it appears that the outsourcing of design has remained constant (Table 3 shows $77.1 \%$ ), showing an insignificant decrease of 2.9 percent. The outsourcing of pre-project planning (or the pre-design phase as it is referred to in this paper) increased from 20.0 percent (Table 3) between 1994 and 1998 to 32.3 percent (Figure 3) in 2006. 
The consistent level of outsourcing of the performance of design and the increase in the outsourcing of pre-design services indicated in our study compared to that of the CCIS study would lead one to believe that owners are increasingly utilizing specialized firms (such as construction and program management firms) to help them with the management functions of the construction life-cycle. The specialization referred to here is the provider's specialization in a service function. That is, a service provider could specialize in design services, in the performance of construction, in operations, etc. The specialization of the service provider (by type of construction) could be general or it too could be specific. For example, they could provide highly focused design services for K-12 schools. Alternatively they could provide general design services for a wide variety of constructed facilities.

A comparison with the CREM study [Bon and Luck 1999] does not support this conclusion however. The CREM data showed a decrease in the amount of outsourcing of management functions. Large decreases in the outsourcing of design management (oversight of design) and maintenance management (operations and maintenance) along with a slight decrease in construction management (oversight of construction) can be seen (see Table 2 and Figure 3). The reader should note, however, that the data contained within the CREM study was based on a lower response rate. Because of these conflicting results, it is difficult to draw definitive conclusions about outsourcing within the construction industry over the past ten years. Rather, these snapshots of data establish that design performance and construction performance have been, and continue to be, heavily outsourced while the management functions of the construction life-cycle are predominantly performed in-house.

\section{CONCLUSIONS}

The data obtained from the survey was obtained from construction owners with between $\$ 37$ billion and $\$ 72$ billion in annual construction spending which accounts for a significant percentage of US non-residential construction spending. The respondents to the survey came from a diversified group of market sectors and company classifications. Due to the diversification and size of the survey population, the results and subsequent conclusions of the survey provide a broad representation of the outsourcing and sourcing patterns of construction owners. It should be noted that the sample respondents belonged specifically to the groups mentioned earlier. Thus, the sample is not a random sample. The data represent the sample population. Still, the data from the survey can be used as a benchmark for future studies, recognizing the limitations and size of the survey itself.

The results showed that the performance of design and the performance of construction were by far the most heavily outsourced of the activities and phases surveyed. This is to be expected since both of these activities require a tremendous amount of resources, both in personnel and assets. For a corporation or organization whose main business is not construction it is difficult to maintain the staff and provide the resources needed to perform all of the design and construction services in-house. While the outsourcing of the activities associated with the performance of design and construction was found to be close to 75 percent, the outsourcing of all other activities ranged from 30 to 40 percent. The outsourcing of operations and maintenance activities was the lowest at just below 30 percent. Clearly owners prefer to do their own maintenance. 
From the results of the sourcing strategy data, a better understanding of the strategies employed by some construction owners for procuring construction life-cycle services can be seen. The largest number of respondents to the survey consistently reported selecting from a small group of service providers to source the phases or activities within the construction process. The one function that varied from this trend was the performance of construction. For the performance of construction, the largest group of respondents reported selecting from numerous service providers when sourcing the performance of construction.

Finally, the comparison of the data for the construction functions showed strong relationships between the amount of outsourcing and the sourcing strategy. It is apparent from the data that for management functions (pre-design, oversight of design, oversight of construction), the larger the percentage that is outsourced the fewer the number of service providers that are used to source the function. It is also apparent for the performance functions (performance of design, performance of construction, and operations and maintenance) that the larger the percentage of work that is outsourced the more service providers are used to source the function. Also, owners appeared to have a clear approach to sourcing the performance of construction because of the agreement in the sourcing strategy used and the amount of outsourcing. Owners did not appear to have a clear approach to sourcing the other functions of the construction life-cycle.

\section{RECOMMENDATIONS}

As a recommendation for practical applications from the conclusions of this research, owners should develop a clear sourcing strategy for their construction program, whether that program is performed entirely in-house, is completely outsourced, or rests somewhere in between. While owners appear to have a clear strategy for sourcing the performance of construction, they should employ a standardized and proven strategy for sourcing all management functions in the construction life-cycle.

As construction becomes more specialized and complicated, and as the cost for an internal construction management staff increases, the outsourcing of management functions will more than likely increase. Service providers, especially construction managers, will begin to market themselves as specialized firms not only with the ability to work within specific market sectors, but also with the ability to perform specific activities throughout the construction life-cycle. Recommendations can also be made based on the finding that owners tend to select from a small group of service providers. Clearly this group is the one establishing a good relationship with the owner and providing their service within the schedule and budget, delivering quality work and products, while efficiently maintaining their own corporate enterprise. Service providers who consistently achieve these objectives will be consistently short-listed. Owners should be wary of the qualifications of each service provider with which they contract. They should use an appropriate sourcing strategy that will provide them with the best quality as well as the best price.

For future research others who might like to conduct surveys should consider the value that could be gained on a sector by sector basis. The work reported herein (see Table 3 ) is based on the entire non-residential construction industry. In addition to such an analysis, perhaps a study of one or a few sectors would be of interest and could be considered. Furthermore, the analysis 
combined public, private, and quasi-public responders. A future study could focus on only one of these organizational types.

\section{ACKNOWLEDGEMENT}

The writers would like to especially acknowledge CMAA and their director Bruce D'Agostino for their support and work on this project. Mr. D'Agostino's guidance was invaluable in providing access to industry professionals and in the development and execution of the survey. The writers would also like to acknowledge the program management focus group and each professional organization that participated in the survey including COAA, CURT, HFI, and CEFPI. Finally, the authors acknowledge and thank each respondent who took time to complete the survey instrument.

\section{REFERENCES}

Bon, R. and Luck, R. (1999). "Outsourcing of Property-Related Management Functions in Europe and North America, 1993-1998." Construction Management and Economics, 17, Pages 409-412.

Bryant, Paul T. (2006). "Decline of the Engineering Class: Effects of Global Outsourcing of Engineering Services." Leadership and Management in Engineering, Volume 6, Number 2, Pages 59-71.

Datamonitor. (2006). Construction \& Engineering in the United States: Industry Profile (Reference Code: 0072-2028). New York: Datamonitor.

Galloway, P. D. (2006). "Survey of the Construction Industry Relative to the Use of CPM Scheduling for Construction Projects." Journal of Construction Engineering and Management, Volume 132, Number 7, Pages 697-711.

Gibson, E., Jantz, G., and Graham, T. (2001). Owner Outsourcing Trends and their Affects on Project Practices and Performance. Technical Report. University of Texas at Austin, Center for Construction Industry Studies.

Greaver, M. F. (1999). Strategic Outsourcing: A Structured Approach to Outsourcing Decisions and Initiative. New York: American Management Association.

Simonson, K. (2006). Quick Facts about the Construction Industry. Associated General Contractors of America. 
Table 1: Outsourcing Percentages for CCIS Study

\begin{tabular}{||l||c|c|c||}
\hline \multicolumn{1}{|c|}{ Function } & High (\%) & Low (\%) & Average (\%) \\
\hline \hline Pre-project Planning & $\mathbf{3 4}(\mathbf{1 9 9 7 )}$ & $\mathbf{6 ( 1 9 9 8 )}$ & $\mathbf{2 0}$ \\
\hline Design & $81(1995)$ & $65(1998)$ & $\mathbf{8 0}$ \\
\hline Procurement & $93(1997)$ & $75(1994)$ & $\mathbf{8 0}$ \\
\hline \hline Overall & $68(1997)$ & $52(1998)$ & 60 \\
\hline
\end{tabular}


Table 2: Incidence of CREM Functions, 1993-1998 [Bon and Luck 1999]

\begin{tabular}{||l||c|c||}
\hline \multicolumn{1}{|c|}{ Function } & $\begin{array}{c}\text { Average } \\
\text { In-House } \\
(\boldsymbol{\%})\end{array}$ & $\begin{array}{c}\text { Average } \\
\text { Outsourced } \\
(\boldsymbol{\%})\end{array}$ \\
\hline \hline Design Management & $\mathbf{5 0}$ & $\mathbf{5 0}$ \\
\hline Construction Management & 58 & 42 \\
\hline Facilities Management & $\mathbf{6 8}$ & 32 \\
\hline Maintenance Management & 56 & 44 \\
\hline
\end{tabular}




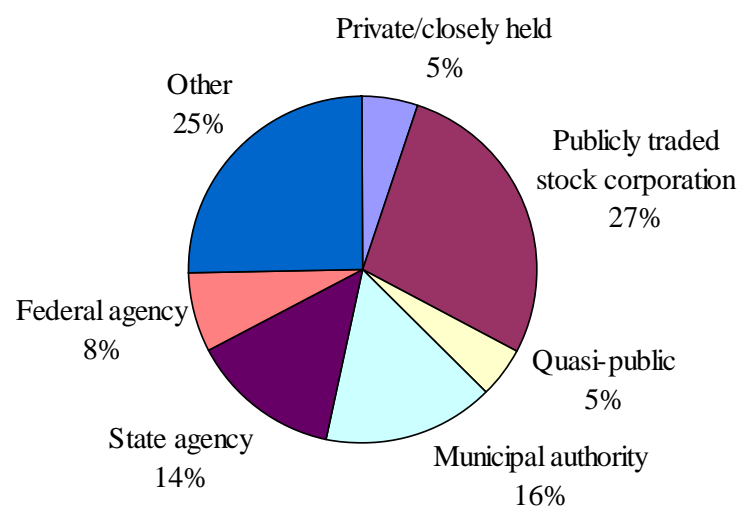

Figure 1: Type of Organization for All Survey Respondents 
Table 3: Market Sectors of Survey Respondents

\begin{tabular}{||l||c|c||}
\hline \multicolumn{1}{|c||}{ Description } & $\begin{array}{c}\text { Number of } \\
\text { Selections }\end{array}$ & Percentage* \\
\hline \hline Education & 60 & $35.5 \%$ \\
\hline Other & 33 & $19.5 \%$ \\
\hline Energy & 33 & $19.5 \%$ \\
\hline Private Office and Professional & 32 & $18.9 \%$ \\
\hline Water Supply/Waste Water Facilities & 23 & $13.6 \%$ \\
\hline Public Safety, Administrative, and Other & 21 & $12.4 \%$ \\
\hline Highways and Streets & 21 & $12.4 \%$ \\
\hline Manufacturing & 20 & $11.8 \%$ \\
\hline Hospitals and Nursing Homes & 15 & $8.9 \%$ \\
\hline Telecommunications & 14 & $8.3 \%$ \\
\hline Commercial & 11 & $6.5 \%$ \\
\hline Amusements and Recreation & 9 & $5.3 \%$ \\
\hline Conservation and Development & 8 & $4.7 \%$ \\
\hline Military Facilities & 4 & $2.4 \%$ \\
\hline Churches/Houses of Worship & 3 & $2.4 \%$ \\
\hline Hotels and Motels & $4.8 \%$ \\
\hline
\end{tabular}

*This number is calculated using the total number of responses (169) 


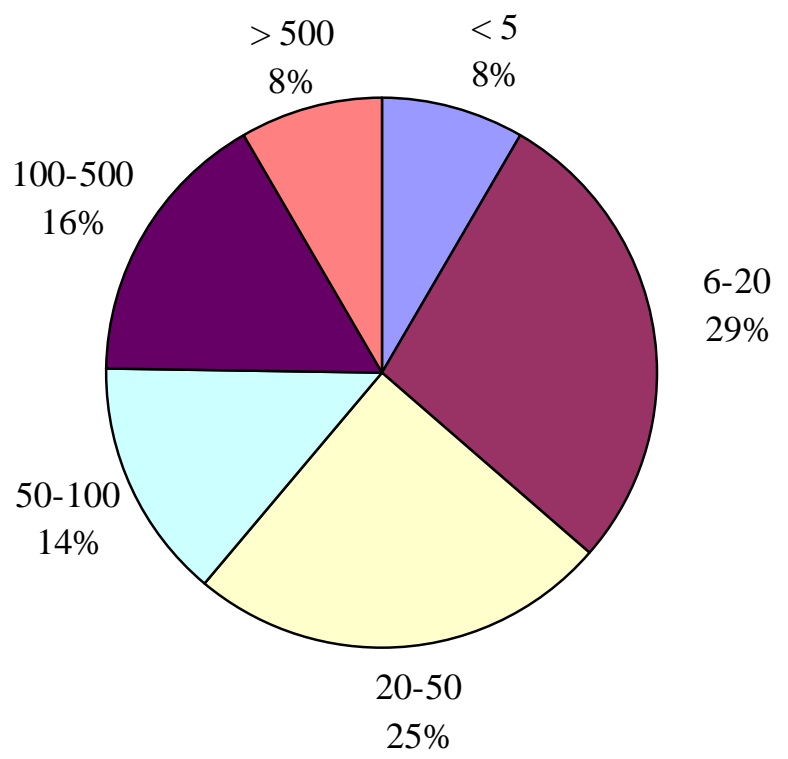

Figure 2: Total Number of Projects Started Per Year by Survey Respondents 
Table 4: Annual Construction Spend for All Survey Respondents

\begin{tabular}{||c||c|c|c||}
\hline $\begin{array}{c}\text { Annual } \\
\text { Construction Spend }\end{array}$ & $\begin{array}{c}\text { Number of } \\
\text { Selections }\end{array}$ & $\begin{array}{c}\text { Total Amount of } \\
\text { Construction Spend- } \\
\text { Low End of Range } \\
\text { (in Millions) }\end{array}$ & $\begin{array}{c}\text { Total Amount of } \\
\text { Construction Spend- High } \\
\text { End of Range } \\
\text { (in Millions) }\end{array}$ \\
\hline \hline <\$1M & 2 & 0 & 2 \\
\hline$\$ \mathbf{1 - \$ 2 5 M}$ & 30 & 30 & 750 \\
\hline $\mathbf{\$ 2 5 - \$ 1 0 0 M}$ & 43 & 1075 & 4300 \\
\hline $\mathbf{\$ 1 0 0 - \$ 5 0 0 M}$ & 55 & 5500 & 27,500 \\
\hline $\mathbf{\$ 5 0 0 M}-\mathbf{\$ 1 B}$ & 18 & 9000 & 18,000 \\
\hline$>$ \$1B & 21 & 21,000 & 21,000 \\
\hline \hline Totals & 169 & 36,605 & $\mathbf{7 1 , 5 5 2}$ \\
\hline
\end{tabular}




\section{Table 5: Functions in the Construction Life-Cycle}

\begin{tabular}{|c|c|}
\hline Function & Description \\
\hline Pre-Design & $\begin{array}{l}\text { The performance of pre-design services includes setting up the business end of } \\
\text { a construction program, classical front end services, and planning activities. } \\
\text { Examples of classical front end services during the pre-design phase include } \\
\text { requirements definition, financial planning, and program schedule. Examples } \\
\text { of planning activities during the pre-design phase include scope and project } \\
\text { definition and program and project planning. }\end{array}$ \\
\hline Oversight of Design & $\begin{array}{l}\text { The oversight of design services involves establishing a process to select the } \\
\text { individual design firm(s) for design phase services of the construction program; } \\
\text { managing the design schedule; and creating the design packages for a } \\
\text { construction program. }\end{array}$ \\
\hline Performance of Design & $\begin{array}{l}\text { Performance of design services involves the development of the design for each } \\
\text { phase or project within the program. }\end{array}$ \\
\hline Oversight of Construction & $\begin{array}{l}\text { The oversight of the construction process typically includes logistics planning, } \\
\text { schedule monitoring, change management, quality assurance and control, and } \\
\text { facility commissioning. The owner's representative or a construction manager } \\
\text { working in the role of an agent typically performs this function. }\end{array}$ \\
\hline Performance of Construction & $\begin{array}{l}\text { Construction performance involves the responsibility of schedule and cost } \\
\text { performance for the construction phase. This function is typically performed by } \\
\text { a general contractor, construction manager at-risk, or through a multi-prime } \\
\text { contract. }\end{array}$ \\
\hline Activation & $\begin{array}{l}\text { Program activation is the process whereby the owner prepares to use a new } \\
\text { facility or facilities. The goals of activation are ensuring that facilities are } \\
\text { prepared and occupancy is achieved in a timely and efficient manner; ensuring } \\
\text { that the intended level of services is achieved from the outset, and providing a } \\
\text { seamless and transparent move from contractor completion to full operation. }\end{array}$ \\
\hline Operations and Maintenance & $\begin{array}{l}\text { Operations and maintenance includes all operations and maintenance } \\
\text { procedures to be performed on the constructed facilities within the program }\end{array}$ \\
\hline
\end{tabular}


Table 6: Outsourcing Results by Number of Respondents

\begin{tabular}{|c|c|c|c|c|c|c|}
\hline Function & $100 \%$ & $\begin{array}{l}\text { 99\%- } \\
75 \%\end{array}$ & $\begin{array}{l}74 \%- \\
50 \%\end{array}$ & $\begin{array}{l}49 \%- \\
25 \%\end{array}$ & $\begin{array}{c}24 \%- \\
1 \%\end{array}$ & $\mathbf{0 \%}$ \\
\hline Pre-Design & 6 & 22 & 20 & 27 & 54 & 39 \\
\hline Oversight of Design & 9 & 26 & 13 & 20 & 38 & 62 \\
\hline Performance of Design & 51 & 72 & 17 & 7 & 16 & 4 \\
\hline Oversight of Construction & 10 & 32 & 29 & 16 & 38 & 43 \\
\hline Performance of Construction & 76 & 46 & 12 & 8 & 11 & 15 \\
\hline Activation & 12 & 23 & 18 & 13 & 44 & 57 \\
\hline Operations and Maintenance & 8 & 11 & 12 & 20 & 59 & 58 \\
\hline
\end{tabular}


Table 7: Midpoints for Answer Choice Ranges

\begin{tabular}{|c|c|}
\hline Range & Mid Point \\
\hline \hline $100 \%$ & $100 \%$ \\
\hline $75 \%-99 \%$ & $87 \%$ \\
\hline $50 \%-74 \%$ & $62 \%$ \\
\hline $25 \%-49 \%$ & $37 \%$ \\
\hline $1 \%-24 \%$ & $13 \%$ \\
\hline $0 \%$ & $0 \%$ \\
\hline \hline
\end{tabular}




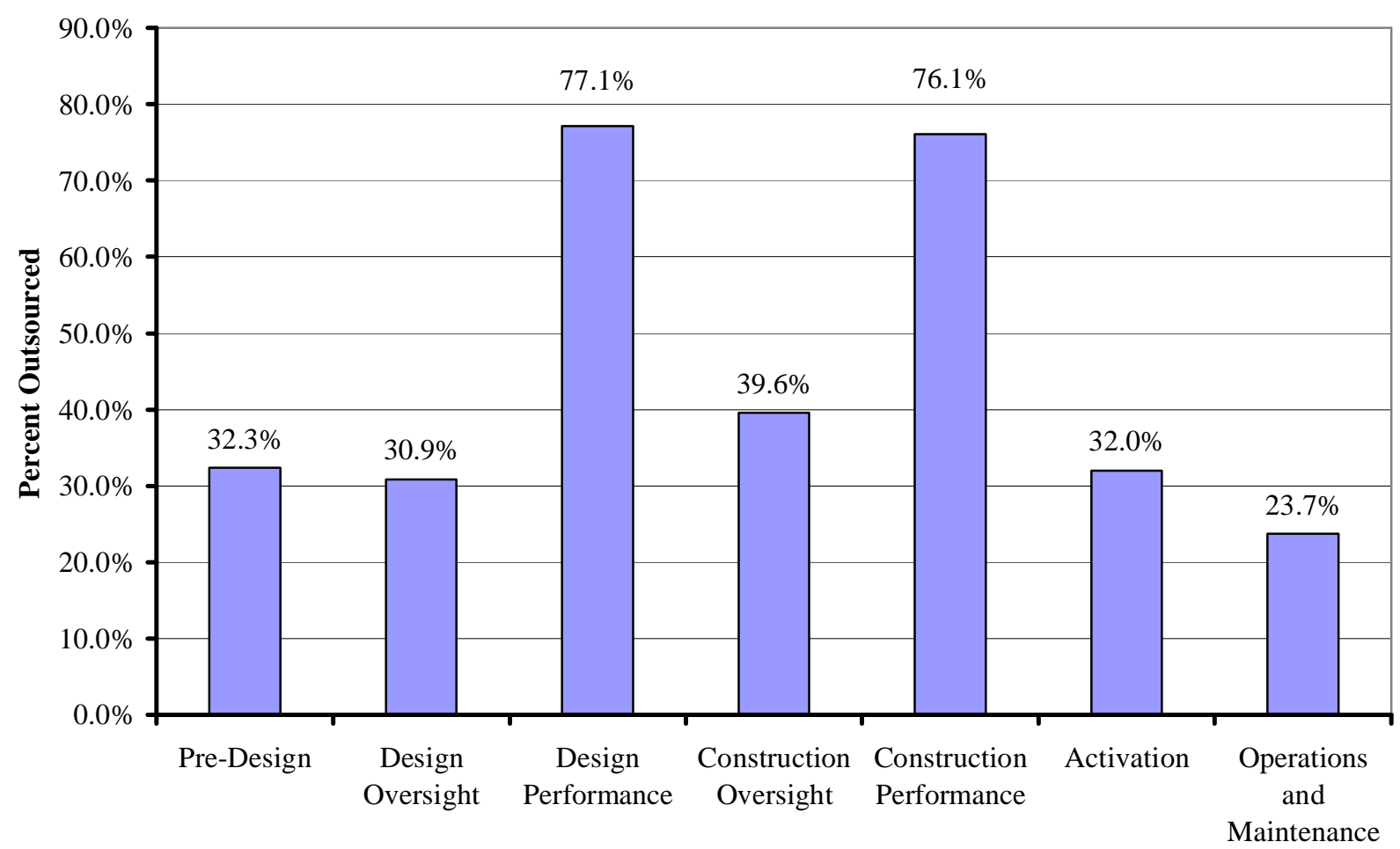

Figure 3: Average of Outsourcing of Project Function 
Table 8: Answer Choices for Questions Related to Sourcing Strategy

\begin{tabular}{||c|c|c||}
\hline $\begin{array}{c}\text { Key } \\
\text { Word(s) }\end{array}$ & Sourcing Strategies & $\begin{array}{c}\text { \# of } \\
\text { Providers }\end{array}$ \\
\hline \hline Different & Always select a different service provider for each project & $>4$ \\
\hline Small Group & Consistently select from a small group (4 or less) of service providers for each project & $3-4$ \\
\hline Frequently & Frequently use the same service provider & $1-2$ \\
\hline Always & Always use the same service provider & 1 \\
\hline In-House & N/A (or do not outsource) & 0 \\
\hline \hline
\end{tabular}


Table 9: Response Totals for Sourcing Strategy

\begin{tabular}{||l||c|c|c|c|c||}
\hline \multicolumn{1}{|c|}{ Function } & Different & Small Group & Frequently & Always & In-House \\
\hline \hline Pre-Design & 30 & 68 & 26 & 6 & 37 \\
\hline Oversight of Design & 25 & 56 & 18 & 6 & 63 \\
\hline Performance of Design & 58 & 82 & 17 & 6 & 4 \\
\hline Oversight of Construction & 28 & 74 & 16 & 9 & 38 \\
\hline Performance of Construction & 71 & 63 & 15 & 3 & 13 \\
\hline Activation & 29 & 60 & 15 & 5 & 51 \\
\hline Operations and Maintenance & 30 & 55 & 17 & 7 & 55 \\
\hline
\end{tabular}




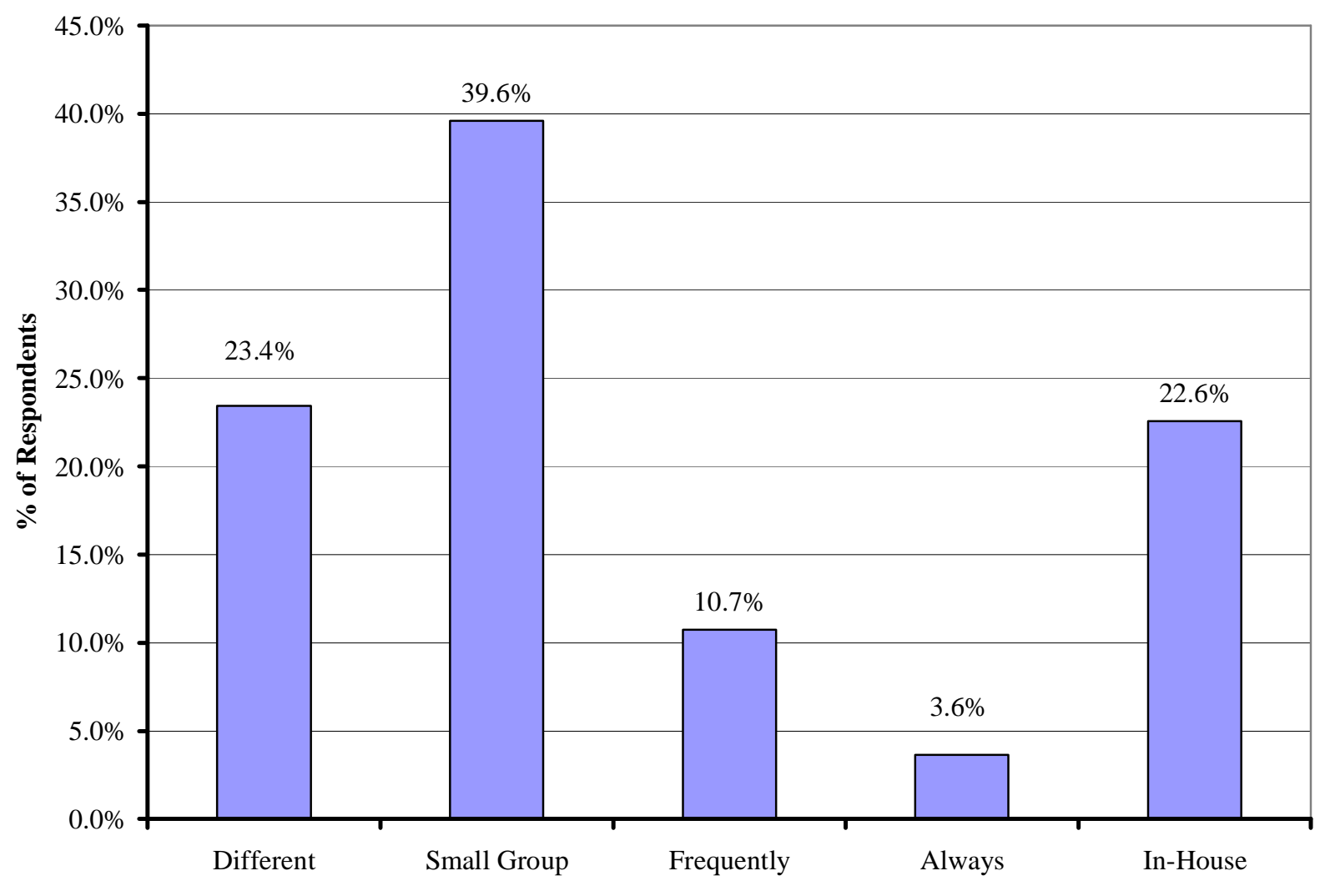

Figure 4: Sourcing Strategy used by Construction Owners 
Table 10: Relationship Between Sourcing Strategy and Outsourcing of Life-Cycle Functions

\begin{tabular}{||l||c|c|c|c||}
\hline \multicolumn{1}{|c||}{ Function } & Different & Small Group & $\begin{array}{c}\text { Frequently } \\
\text { the Same }\end{array}$ & $\begin{array}{c}\text { Always the } \\
\text { Same }\end{array}$ \\
\hline \hline Pre-Design & $\mathbf{3 9 . 0 \%}$ & $43.8 \%$ & $33.9 \%$ & $\mathbf{6 4 . 2 \%}$ \\
\hline Oversight of Design & $47.2 \%$ & $49.7 \%$ & $42.8 \%$ & $72.6 \%$ \\
\hline Performance of Design & $85.1 \%$ & $75.3 \%$ & $80.6 \%$ & $55.9 \%$ \\
\hline Oversight of Construction & $47.5 \%$ & $52.7 \%$ & $52.0 \%$ & $64.9 \%$ \\
\hline Performance of Construction & $\mathbf{9 4 . 4 \%}$ & $\mathbf{7 8 . 7 \%}$ & $\mathbf{5 8 . 9 \%}$ & $\mathbf{4 5 . 5 \%}$ \\
\hline Activation & $63.5 \%$ & $40.2 \%$ & $45.6 \%$ & $62.1 \%$ \\
\hline Operations and Maintenance & $36.5 \%$ & $35.2 \%$ & $25.6 \%$ & $28.5 \%$ \\
\hline
\end{tabular}

